doi:10.12662/2359-618xregea.v9i3.p66-80.2020

ARTIGOS

\section{AVALIAÇÃO DO ECOSSISTEMA DE INOVAÇÃO DE UMA UNIVERSIDADE NA REGIÃO SUL DO BRASIL}

\author{
EVALUATION OF THE INNOVATION ECOSYSTEM \\ OF A UNIVERSITY IN SOUTH REGION OF BRAZIL
}

\section{RESUMO}

O conhecimento gerado pelas universidades pode contribuir, de forma estratégica, para o desenvolvimento dos ecossistemas de inovação. As universidades são atores importantes nas articulações junto a governos, empresas e sociedade. Dada a importância desse papel, há um esforço da comunidade acadêmica em avaliar os ecossistemas de inovação em que as universidades estão presentes. Assim, o objetivo deste trabalho é analisar o ecossistema de inovação de uma universidade da região Sul do Brasil por meio de um modelo chamado de estrutura de capacidades dinâmicas. A universidade estudada foi analisada sob os eixos: pesquisa, educação e programas de suporte; estudantes e grupos de doutorado; incubadoras, aceleradoras e espaços de coworking; investidores, mentores e redes de alunos e treinamentos, competições, eventos e seminários. Concluiu-se que o ecossistema está no estágio de desenvolvimento conforme o modelo utilizado para análise e que, entre seus pontos fortes, estão as parcerias firmadas entre os atores do ecossistema.

Palavras-chave: Ecossistemas de Inovação. Inovação em Universidades. Avaliação de Ecossistemas.

\begin{abstract}
The knowledge generated by universities can contribute, in a strategic way, to the development of innovation ecosystems. Universities are important actors in the articulations with governments, companies and society. Given the importance of this role, there is an effort by the academic community to evaluate the innovation ecosystems in which universities are present. Thus, the objective of this paper is to analyze the innovation ecosystem of a university in the South of Brazil through a model called dynamic capacity structure. The university studied was analyzed under the axes: research, education and support programs; students and doctorate groups; incubators, accelerators and coworking spaces; investors, mentors and student networks and training, competitions, events and seminars. It was concluded that the ecosystem
\end{abstract}


is in the development stage according to the model used for analysis and that, among its strengths, are the partnerships established between the actors of the ecosystem.

Keywords: Innovation Ecosystems. Innovation in Universities. Ecosystem Assessment.

\section{INTRODUÇÃO}

A Universidade, como local gerador de conhecimento, possui um importante papel no impacto que tais conhecimentos trazem à sociedade. Atualmente, ela deixa de ser atuante apenas na formação do ensino, da pesquisa e extensão, para ser uma instituição modeladora de comportamento e de habilidades empreendedoras para o desenvolvimento da inovação, gerando impactos diretos e positivos para a sociedade (BAGNATO, 2012).

Segundo o ranking Global Innovation Index (GII), que mede os maiores aglomerados mundiais de atividades de ciência e tecnologia (DUTTA; LANVIN; WUNSCH-VINCENT, 2018), a posição do Brasil no 64 lugar em 2018 é um indício que ressalta a necessidade de coordenarem ações para fomentar a inovação no País, envolvendo a iniciativa privada, o Governo e as universidades, entre outros atores. A participação das universidades tem merecido atenção devido à mudança do seu papel nos últimos anos. Em um estudo sobre empreendedorismo e inovação nas universidades brasileiras, promovido pela Endeavor e pelo Sebrae (2017) em mais de 70 instituições de ensino superior, os resultados refletem que muito precisa ser feito nesta área. Nesse sentido, a Universidade, tendo a inovação e os ambientes de inovação como fundamento, passa a ter um papel de destaque no processo de desenvolvimento econômico e social. Uma universidade tem a missão complexa de propiciar um contexto promotor da inovação.

O que caracteriza uma universidade é seu ambiente multi-institucional, ea denominação de ecossistema é apropriada. Conforme Etzkowitz $e$ Zhou (2017), a presença de uma universidade no ecossistema local é crucial para o desenvolvimento da inovação, pois ela é um ator estratégico nas interações com governos e empresas. Tendo em vista o papel da universidade no desenvolvimento dos ecossistemas de inovação, surge a seguinte questão: como avaliar o ambiente de inovação das universidades e a sua relação com o ecossistema? Nesse contexto, o objetivo deste artigo é analisar o ecossistema de inovação de uma universidade da região Sul do Brasil, visto que a universidade desempenha um papel essencial e complexo na transformação da sociedade. Para isso, será utilizado o modelo de capacidades dinâmicas proposto por Heaton, Siegel e Teece (2019). Alguns estudos recentes abordam a temática dos ecossistemas de inovação envolvendo universidades (BENITEZ; AYALA; FRANK, 2020; TOLSTYKH; GAMIDULLAEVA; SHMELEVA, 2020). Entretanto, esta pesquisa justifica-se pela aplicação prática de um modelo, permitindo que novos conhecimentos sejam gerados por meio da análise de diferentes contextos.

Este artigo está organizado da seguinte forma: primeiro, no referencial teórico, descrevemos (i) o que são ecossistemas de inovação; (ii) o papel das universidades nos ecossistemas de inovação; e (iii) um modelo de avaliação de ecossistemas universitários - a estrutura de capacidades dinâmicas. Na próxima seção, o método de pesquisa é definido. Em seguida, as análises referentes ao ecossistema estudado são apresentadas na seção resultados. Por fim, a seção de conclusão resume os achados desta pesquisa e sugere tópicos para estudos futuros.

\section{REFERENCIAL TEÓRICO}

\subsection{A INOVAÇÃO E SEU ECOSSISTEMA}

Conhecimento e inovação apresentam uma relação direta e proporcional: quanto mais conhecimento houver, mais inovações irão surgir. Esses são elementos com intrínseca conexão, pois não há inovação sem conhecimento, e é por meio do saber que novas ideias são ge- 
radas. O conhecimento é visto como um recurso essencial às organizações, já que não basta apenas possuir dados (registros isolados) ou informações (dados com tratamento), pois é o conhecimento que envolve a informação aplicada em busca de um determinado objetivo que gerará a base para a inovação. Tidd e Bessant (2015) ressaltam que a inovação é uma questão de conhecimento, ou seja, é criar novas possibilidades por meio da combinação de diferentes conjuntos de conhecimentos.

As fontes que promovem as inovações encontram-se não apenas no âmbito interno da organização, mas também no ambiente externo. É preciso observar e estar atento para o conjunto no qual as variáveis internas e externas convivem, gerando resultados que agreguem valor à organização. Inovação é uma atividade associada à sobrevivência e ao crescimento das empresas no ambiente concorrencial: é o processo de busca, seleção, implementação e captura de valor, relacionadas à inovação (TIDD; BESSANT, 2015). É no âmbito interno, com os procedimentos e as atividades rotineiras, e no panorama externo - fatores políticos econômicos, sociais, tecnológicos, ambientais e legais juntamente com a análise da concorrência e das necessidades e dos desejos do público-alvo que se captam os elementos que fazem que a inovação proposta atinja os resultados almejados na empresa inovadora (SILVA et al., 2018).

De acordo com Dodgson e Gann (2014), a inovação possui muitas definições, tipologias e níveis e remete ao que acontece quando um novo pensamento é valorizado e introduzido com êxito nas organizações. Para o Manual de Oslo: "uma inovação é a implementação de um produto (bem ou serviço) novo ou significativamente melhorado, ou um processo, ou um novo método de marketing, ou um novo método organizacional nas práticas de negócios, na organização do local de trabalho ou nas relações externas." (OCDE, 2005, p. 55).

Tidd e Bessant (2015) apontam os seguintes aspectos da inovação passíveis de exploração: tempo ou oportunidade, nível de inovação, inovação descontínua, plataformas e famílias de inovação; grau de novidade. O grau da inovação pode ser radical ou incremental. A inovação incremental interessa-se pelo aprimoramento de algum aspecto de produtos já existentes, ofertando atualizações coerentes com as tendências ou as necessidades demonstradas pelos clientes. Já a inovação radical transforma a forma como um produto é percebido e usado, de modo a quebrar paradigmas estabelecidos pela sociedade (SILVA et al., 2018). Isso está de acordo com Audy (2017) que, conforme o autor, existem dois tipos de inovação ilustrados na figura 1: incremental ou disruptiva. Assim, a inovação incremental gera melhorias contínuas e provê sustentação para as diversas fases do ciclo de vida de um produto ou processo. Envolve a aplicação de melhorias, normalmente modestas e sem elevação do patamar tecnológico no qual se aplica; enquanto a inovação disruptiva está associada à ruptura de paradigmas e às mudanças radicais que geram um novo patamar tecnológico. São dramáticas, gerando novas demandas, mercados, processos e aplicações econômicos e sociais.

Figura 1 - Tipos de Inovação.

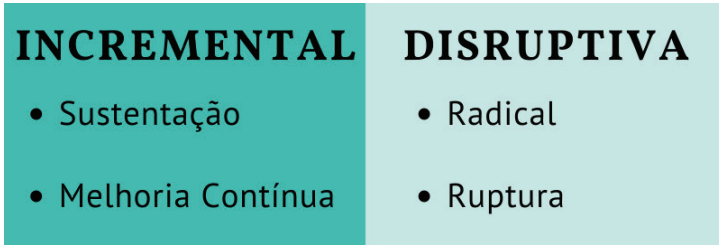

Fonte: elaboração própria (2019).

Tratando-se de plataformas e famílias de inovação, as empresas buscam manter uma base comum para a oferta de diferentes produtos, criando plataformas que podem ser exploradas comercialmente de formas diferentes com acréscimos que fazem que o valor agregado seja diferente (SILVA et al., 2018). A inovação descontínua indica mudanças nos padrões adotados como rotina, de modo a redefinir os espaços e limites: novas características surgem em mercados completamente novos e descontinuam a inovação que vigorava na época.

A respeito do nível de inovação, as mu- 
danças em níveis superiores impactam os níveis inferiores do sistema, de modo que atualizações se tornam obrigatórias em função da não compatibilidade das mesmas funcionalidades com requisitos diferentes (SILVA et al., 2018). Observamos que as oportunidades podem modificar-se ao longo dos anos, já que as inovações vigentes tendem a cair no esquecimento ou a ficar desatualizadas. Assim, as empresas devem permanecer em uma constante busca pela inovação seguinte, já que a atual corre o risco de tornar-se obsoleta em um futuro próximo (SILVA et al., 2018).

O construto "ecossistema de inovação" surgiu em meados da década de 1990. Foi baseado no conceito de ecossistemas de negócio, que é entendido como uma comunidade econômica que interage com um conjunto de organizações e indivíduos pertencentes ao mundo dos negócios, produzindo bens e serviços de valor para o cliente. $\mathrm{O}$ conceito de ecossistema de inovação surgiu como um termo difuso para descrever a crescente complexidade da inovação, envolvendo a interação entre os atores e seus contextos. Logo, os ecossistemas de inovação, como um processo sistêmico, crescem dentro de uma rede de relações interorganizacionais, que promovem a inter-relação e a integração do conhecimento de diferentes atores, por exemplo, universidades, centros de pesquisa, empresas, instituições e governos (MOORE, 1993).

Jackson (2011, p. 2) define os ecossistemas de inovação como "complexas relações que são formadas entre atores ou entidades, cujo objetivo funcional é permitir o desenvolvimento tecnológico e a inovação." Nesse sentido, os ecossistemas incluem capital humano (estudantes, professores, funcionários, gestores, pesquisadores), entidades (universidades, empresas, centros, institutos, agências de financiamento, decisões políticas) e recursos materiais (fundos, equipamentos, instalações). Percebe-se que o envolvimento de diversos atores é essencial no fluxo de inovação, conhecimento e aprendizagem, por meio de mecanismos de colaboração e complementaridade, bem como a universidade pode representar um ator estratégico nos ecossistemas (ETZKOWITZ; ZHOU, 2017; TORLIG; RESENDE JÚNIOR, 2018).

\subsection{ECOSSISTEMAS DE INOVAÇÃO EM UNIVERSIDADES}

Destaca-se, nos estudos sobre ecossistemas de inovação, o papel de protagonismo que a Universidade passa a ter no processo de desenvolvimento econômico e social. Esse novo modo de produção de conhecimento nas universidades situa-se em um contexto de aplicabilidade, ou seja, são desenvolvidas pesquisas mediante a necessidade de resolver problemas práticos, devido à formação de redes que ampliam a interatividade entre a universidade e meio (ETZKOWITZ, 2003). Nesse sentido, as universidades e os institutos de pesquisa podem desempenhar um papel crucial nos ecossistemas de inovação, facilitando a interação entre a pesquisa e sua aplicação comercial, estimulando a produção e a difusão de conhecimento. Nesse contexto, as universidades não só produzem e acumulam o conhecimento, mas há uma troca ativa com os diversos atores, capaz de gerar aprendizagem e inovação por meio de redes e interligações de atividades que atravessam fronteiras (YOUTIE; SHAPIRA, 2008). A universidade assume um papel de importante na formação de pessoas, como fonte para geração de ideias, formando profissionais com habilidades empreendedoras. As universidades são capazes de tornar o ecossistema de inovação um lugar de formação e de desenvolver mecanismos eficazes de transferência de tecnologia e inovações científicas, representando a base da competitividade dos países e suas alianças geopolíticas (TORLIG; RESENDE JÚNIOR, 2018). As redes do Ecossistema de Inovação de uma Universidade também se relacionam com o ambiente local. Dentro deste contexto, é importante destacar que, segundo o Ministério da Ciência, Tecnologia, Inovações e Comunicações - MCTIC (BRASIL, 2018), os ambientes de inovação são caracterizados por duas dimensões: os "ecossistemas", que se constituem 
em espaços como parques, polos científicos e tecnológicos e cidades inteligentes; e os "mecanismos promotores de empreendimentos" que apoiam o desenvolvimento de empresas nascentes de base tecnológica, por exemplo, incubadoras, aceleradoras, entre outros.

Surge, assim, um novo modelo de ambientes de geração de riqueza e crescimento econômico e social, utilizando nomes diferentes, mas com o significado comum: os Parques Científicos, tecnológicos ou de Pesquisa. Esses novos ambientes, além de envolverem pessoas com conhecimento e com talento, envolvem, também, outros fatores em comum como a (i) participação de empresas de tecnologias e de inovação, (ii) a relação com Universidades e Centros de Pesquisa, (iii) serviços especializados qualificados, como gestão da propriedade intelectual, acesso a redes internacionais, contato com investidores e acesso à capital de risco, uso de laboratórios de pesquisa e desenvolvimento compartilhados, (vi) espaços de convivência, descompressão e tecnologias limpas e (v) acesso a redes locais e globais, de negócios, de ciência e de tecnologias (AUDY, 2017).

Esses Parques Tecnológicos, de Pesquisa ou de Ciências, também incorporam mecanismos de geração de novos empreendimentos de base tecnológica, como as incubadoras e outros dispositivos para a geração de empreendimentos inovadores e de alto desempenho, como incubadoras, aceleradoras, espaços de coworking e living labos (AUDY, 2017). Ainda conforme o autor, existe a percepção de que as características dos parques são comuns, podendo-se listar que: (a) são instituições híbridas, pois abrigam empresas inovadoras de diversos portes e procedências, bem como centros e laboratórios de investigação de instituições de ensino e pesquisa; e (b) geram intervenções urbanas de impacto no local onde se situam, com repercussões nos instrumentos públicos do seu ambiente.

As interações entre universidade, indústria e governo formam o que é conhecido como a "hélice tríplice" de inovação e empreendedorismo, sendo a chave para o crescimento econômico e o desenvolvimento social baseados no conhe- cimento, assumindo uma postura proativa na colocação do conhecimento em prática e na ampliação dos insumos que criarão o conhecimento acadêmico. A Hélice Tríplice pode ser definida como um modelo de inovação em que a universidade, a indústria e o governo, como esferas institucionais primárias, interagem para promover o desenvolvimento por meio da inovação e do empreendedorismo; é um processo em desenvolvimento contínuo em que a meta é criar um ecossistema para inovação e empreendedorismo (ETZKOWITZ; ZHOU, 2017). Assim, as políticas públicas de incentivo à inovação podem dinamizar ainda mais esse processo, tendo em vista os diversos benefícios oferecidos nas agendas governamentais para alavancar a atividade inovadora das empresas (SILVA et al., 2018).

Segundo Trott (2012), as alianças estratégicas beneficiam os atores de um mercado, contribuindo para que haja um aumento na atividade inovadora por meio da colaboração. Podem ser citadas, como exemplo de alianças, o licenciamento, as relações de fornecimento, a terceirização, as joint ventures, as parcerias não contratuais, os consórcios de pesquisa e desenvolvimento (P\&D), os clusters, as redes industriais e as redes de inovação. As razões para essas alianças se devem, por exemplo, devido ao acesso à tecnologia e ao compartilhamento do risco de desenvolvimento de uma tecnologia.

$\mathrm{O}$ conceito de inovação aberta também está alinhado às fontes externas. $\mathrm{O}$ conceito fechado, de investir em recursos apenas no âmbito interno, vem sendo substituído pela noção da existência de outras possibilidades para alavancar as fontes de inovação existentes, como a interação entre fontes internas e externas. As parcerias com universidades, incubadoras de empresas e interações com clientes, fornecedores e comunidade são exemplos de conexões que se estabelecem como canais de diálogo constante e que podem promover a inovação de forma aberta (CHESBROUGH, 2006, 2003). Assim, na inovação aberta, o processo de inovação evolui com a participação de agentes externos e vínculos com partes que se situam fora da empresa (TROTT, 2012). 
Desse modo, observa-se que um elemento-chave para a inovação regional é a presença de uma universidade empreendedora, cujos alunos e professores buscam, ativamente, os resultados úteis para suas pesquisas. A universidade é assim uma instituição fundamental para as sociedades baseadas no conhecimento (ETZKOWITZ; ZHOU, 2017), sendo necessário avaliá-las apropriadamente no que tange à inovação.

\subsubsection{Modelos de avaliação de ecossiste- mas em universidades}

\subsubsection{Modelo de Capacidades Dinâmicas}

O termo Capacidades Dinâmicas é uma tradução aproximada da expressão Dynamic Capabilities em inglês. Na definição inicial proposta por Teece, Pisano e Shuen (1997), a capacidade dinâmica é definida como a habilidade de uma empresa em integrar, construir e reconfigurar competências externas e internas em ambientes de mudança rápida. As competências são entendidas como o conjunto de rotinas e processos organizacionais, cujo desempenho é proporcionado pela posse de ativos específicos, difíceis ou impossíveis de imitar. A dinâmica é entendida como situações em que há mudanças rápidas na tecnologia e forças de mercado que exercem efeitos retro alimentadores nas empresas (TEECE; PISANO; SHUEN, 1997).

As categorias mais importantes de capacidades dinâmicas foram agrupadas por razões pragmáticas em recursos para (1) detectar e moldar oportunidades e ameaças, (2) aproveitar oportunidades e (3) manter a competitividade por meio do aprimoramento, combinação, proteção e, quando necessário, reconfigurar os ativos intangíveis e tangíveis da organização (TEECE; PISANO; SHUEN, 1997). Apesar de a origem das capacidades dinâmicas ter sua base na teoria econômica, por meio de análises de competição no mercado, elas podem ser estudadas e aplicadas em setores diferentes como universidades e setor público, como forma de melhorar a eficiência, a eficácia e a efetividade (PABLO et al., 2007).
As universidades têm muitas semelhanças com as empresas com fins lucrativos: grandes orçamentos, uma série de partes interessadas com objetivos conflitantes e uma forte regulamentação. Consequentemente, Capacidades dinâmicas, um modelo desenvolvido para o gerenciamento estratégico da empresa, podem ser úteis no cenário universitário. É fundamentalmente uma estrutura para guiar uma organização ou instituição, procurando alcançar e manter a aptidão empreendedora. Uma abordagem empreendedora ajudará os líderes da universidade a identificar e lidar com certos desafios relacionados à formulação de uma estratégia e determinar quais recursos eles precisam enfrentar e alcançar os objetivos das partes interessadas relacionadas aos fatores internos da universidade (TEECE, 2018).

Fortes capacidades dinâmicas demoram a ser construídas e devem ser mantidas e, periodicamente, renovadas, para que se transformem, à medida que as circunstâncias mudam. A criação de capacidades fortes normalmente envolve a promoção de uma cultura organizacional colaborativa. Essas características são particularmente relevantes para o cenário universitário. $\mathrm{O}$ modelo de capacidades dinâmicas auxilia no entendimento de como as estratégias acerca de tecnologia e inovação estão relacionadas no ecossistema (HEATON; SIEGEL; TEECE, 2019). Esse modelo possui cinco eixos principais, os quais são apresentados na figura 2 .

Figura 2 - Modelo de capacidades dinâmicas

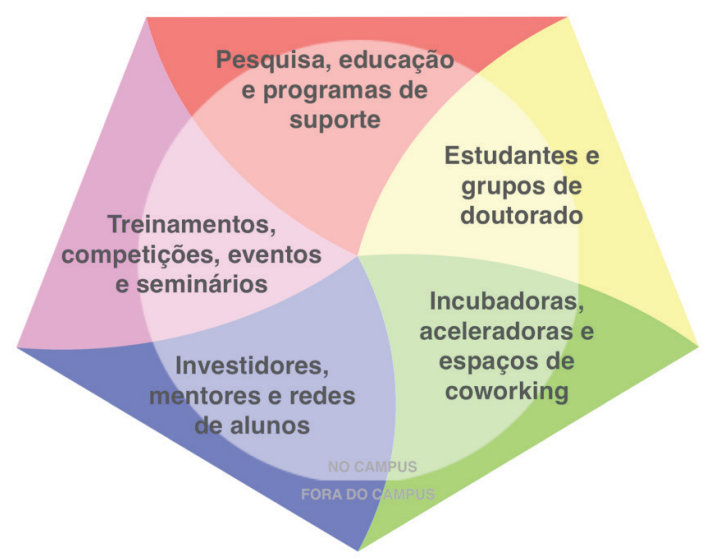

Fonte: baseada em Heaton, Siegel e Teece (2019). 
Os ecossistemas evoluem ao longo do tempo, bem como o papel da universidade. Para Heaton, Siegel e Teece (2019), os ecossistemas de inovação podem-se enquadrar em um desses estágios: inicial, em desenvolvimento ou em renovação. A figura 3 apresenta a síntese desses estágios.

\section{METODOLOGIA}

Esta pesquisa utiliza uma abordagem qualitativa e tem o estudo de caso como estratégia. O estudo de caso é utilizado para descrever um fenômeno em profundidade, tendo o pesquisador como papel de observador (YIN,

Figura 3 - Estágios dos ecossistemas de inovação

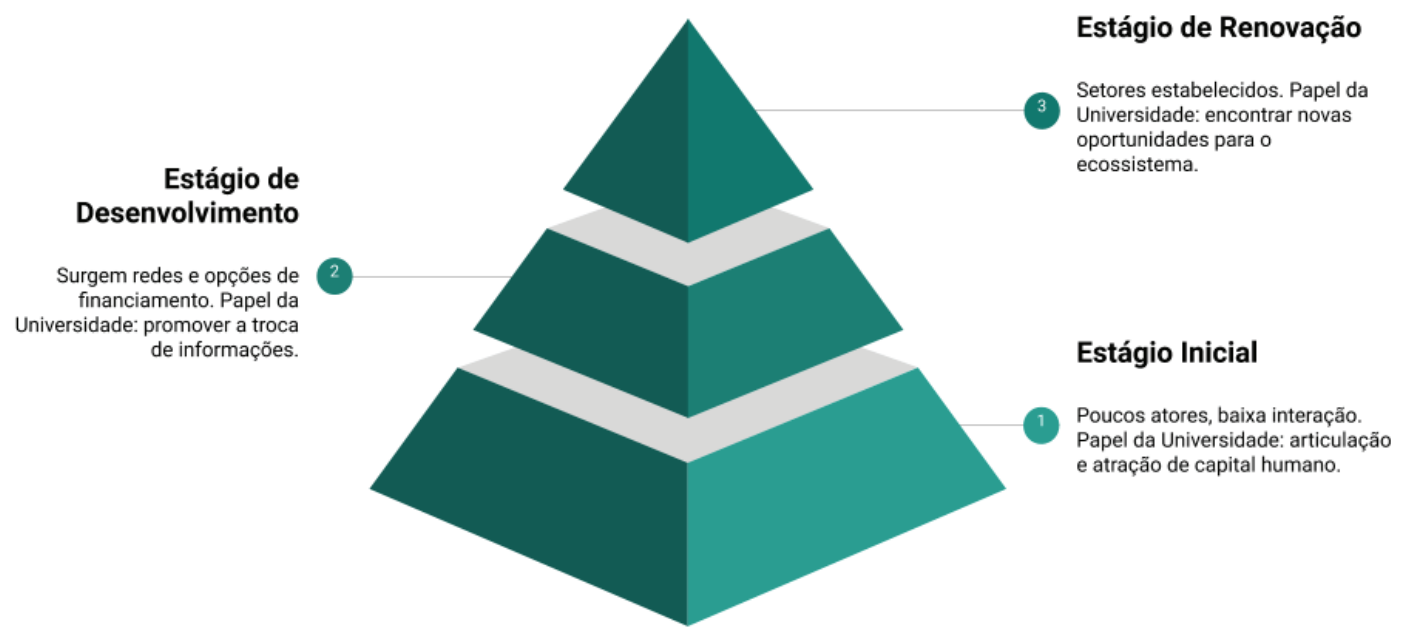

Fonte: baseada em Heaton, Siegel e Teece (2019).

No estágio inicial, os atores do ecossistema são raros e interagem pouco, embora a universidade assuma, fortemente, um papel de articulação. A universidade também pode contribuir atraindo capital humano e garantindo a presença de pesquisa e tecnologia no ecossistema. No estágio de desenvolvimento, as redes e as opções de financiamento começam a se estabelecer, e a universidade assume um papel de consolidação. Nessa fase, são necessárias políticas governamentais mais específicas para o desenvolvimento do ecossistema, e a universidade pode promover a troca de informações e o empreendedorismo por meio de eventos, workshops e palestras. Por fim, na fase de renovação, os setores estabelecidos entram em um estágio de estagnação, e a atividade de inovação muda para setores emergentes. Nesse momento, a universidade pode auxiliar o ecossistema a encontrar novas oportunidades, reduzindo o risco de declínio do ecossistema de inovação (HEATON; SIEGEL; TEECE, 2019).
2015). O estudo de caso é um método de pesquisa empírico, utilizado para investigações de fenômenos contemporâneos, principalmente quando os limites entre esse fenômeno e o seu contexto não estão claramente definidos (EISENHARDT; GRAEBNER, 2007; YIN, 2015). As etapas seguidas para execução deste trabalho são apresentadas na figura 4.

Figura 4 - Método de Pesquisa

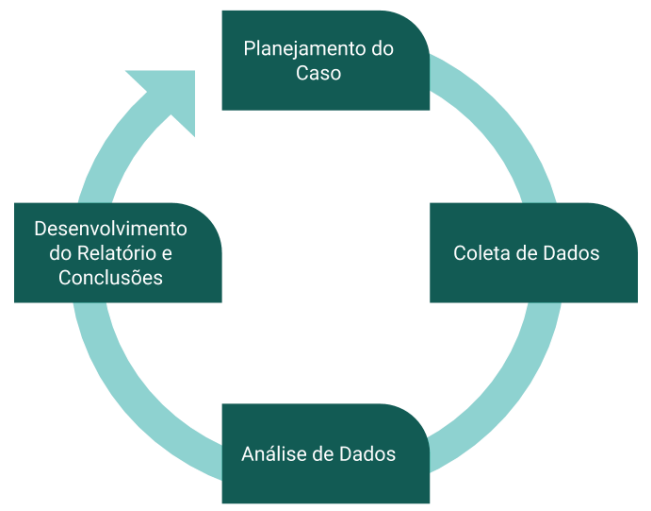

Fonte: elaboração própria (2019). 
Na etapa de planejamento do caso, as unidades de análise são selecionadas conforme o levantamento teórico realizado (YIN, 2015). Neste trabalho, optou-se pelo estudo de caso único, uma vez que o projeto analisado ecossistema de inovação de uma universidade no sul do Brasil - possui caráter representativo. Esse caráter representativo se dá por a universidade ser única no contexto do seu ecossistema. Além disso, os fenômenos estudados por meio do estudo de caso normalmente são de natureza complexa e estão dentro de um contexto real (DRESCH; LACERDA; ANTUNES JÚNIOR, 2015). O caso também pode ser definido como incorporado, visto que se trata de um único contexto, mas de unidades de análise distintas. As unidades de análise utilizadas foram as categorias apresentadas por Heaton, Siegel e Teece (2019), baseadas no caso da Universidade de Berkeley. As categorias são: (1) pesquisa, educação e programas de suporte; (2) estudantes e grupos de doutorado; (3) incubadoras, aceleradoras e espaços de coworking; (4) investidores, mentores e redes de alunos e (5) treinamentos, competições, eventos e seminários.

A coleta de dados baseou-se na pesquisa documental. Conforme Yin (2015), os dados coletados por meio de documentos, relatórios e artigos publicados na mídia possuem como vantagens estabilidade e ampla cobertura. No site da universidade objeto deste estudo, os dados foram considerados estáveis, uma vez que podem ser consultados mais de vez, e também de ampla cobertura, visto que o período compreendido pelas publicações é longo e abarca diversos eventos e ambientes. Além do site da universidade, foram consultados relatórios inovação da região, como o Panorama do Setor de Tecnologia Catarinense (2019) e sites relacionados a outros atores do ecossistema, como empresas e incubadoras. Buscou-se localizar nos documentos analisados os atores presentes no ecossistema e suas interrelações.

$\mathrm{Na}$ etapa de análise de dados, buscou-se desenvolver uma narrativa do caso com a estrutura de capacidades dinâmicas apresentada por Heaton, Siegel e Teece (2019). Os elementos presentes em cada uma das categorias selecionadas foram elencados e comparados com o caso da Universidade de Berkeley. Além disso, buscou-se avaliar o nível de maturidade do ecossistema estudado. Por fim, as conclusões da pesquisa foram explanadas e consolidadas na forma deste estudo.

As etapas do método de trabalho foram divididas em um conjunto de atividades, visando à melhor operacionalização da pesquisa. A tabela 1 apresenta as atividades envolvidas em cada uma das etapas da metodologia.

Tabela 1 - Atividades envolvidas

\begin{tabular}{lll}
\hline \multicolumn{1}{c}{ Etapa } & \multicolumn{1}{c}{ Atividades } & \multicolumn{1}{c}{ Entrega } \\
\hline $\begin{array}{l}\text { Planejamento do } \\
\text { Caso }\end{array}$ & $\begin{array}{l}\text { Definir tipo de } \\
\text { caso }\end{array}$ & $\begin{array}{l}\text { Caso único: análise do ecossistema de inovação } \\
\text { de uma universidade }\end{array}$ \\
\hline & Definir contexto & Universidade da Região Sul do Brasil \\
\hline & $\begin{array}{l}\text { (1) pesquisa, educação e programas de suporte; } \\
\text { de análise }\end{array}$ & $\begin{array}{l}\text { (2) estudantes e grupos de doutorado; (3) incu- } \\
\text { badoras, aceleradoras e espaços de coworking; } \\
\text { (4) investidores, mentores e redes de alunos e (5) } \\
\text { treinamentos, competições, eventos e seminários }\end{array}$ \\
\hline & $\begin{array}{l}\text { Definir fontes de } \\
\text { evidência a serem } \\
\text { utilizadas }\end{array}$ & Fonte de dados selecionada: documental \\
\hline
\end{tabular}




\begin{tabular}{lll}
\hline & $\begin{array}{l}\text { Analisar relatórios } \\
\text { e artigos publica- } \\
\text { dos na mídia }\end{array}$ & $\begin{array}{l}\text { Informações sobre o ecossistema coletadas em } \\
\text { relatórios, artigos publicados e sites relacionados }\end{array}$ \\
\hline Análise de Dados & $\begin{array}{l}\text { Descrever contex- } \\
\text { to do caso estu- } \\
\text { dado }\end{array}$ & Entendimento do contexto e suas particularidades \\
\hline $\begin{array}{l}\text { Modelar ecossis- } \\
\text { tema }\end{array}$ & $\begin{array}{l}\text { Ecossistema do caso estudado modelado, consi- } \\
\text { derando as unidades de análise definidas }\end{array}$ \\
$\begin{array}{l}\text { Desenvolvimento do } \\
\text { Relatório e Conclu- } \\
\text { sões }\end{array}$ & $\begin{array}{l}\text { Explicitar apren- } \\
\text { dizado }\end{array}$ & $\begin{array}{l}\text { Descrição do aprendizado e proposta de estudos } \\
\text { futuros }\end{array}$ \\
\hline
\end{tabular}

Fonte: elaboração própria (2019).

A aplicação das etapas e suas respectivas atividades permitiram que a pesquisa se desenvolvesse. A seguir, são apresentados os resultados obtidos.

\section{RESULTADOS}

A universidade estudada situa-se em uma região na qual as empresas de base tecnológica já são líderes na geração de tributos municipais. Assim, é uma região com alto potencial para inovação e empreendedorismo. Nesse contexto, a universidade é apontada como personagem protagonista na evolução do ecossistema de inovação da região, sendo o marco inicial a sua criação. Desde então, a universidade vem atuando de forma ativa em prol do ecossistema. A instituição já foi reconhecida como "Melhor Universidade Empreendedora do Brasil" em uma edição do prêmio Startup Awards.

O reconhecimento principal do papel da universidade está nos talentos atraídos e desenvolvidos no âmbito da instituição de ensino. O quesito capital humano é um dos pontos fortes da região, sendo o segundo estado com maior percentual de alunos do ensino superior voltados à tecnologia (ACATE, 2019). Ademais, percebe-se grande integração entre a universidade eos demais atores do ecossistema da região, o que fortalece ainda mais o espírito inovador e disponibiliza aos alunos e professores estruturas adequadas para desenvolvimento. $\mathrm{Na}$ cidade sede da instituição, foi traçada a "Rota da Inovação", que liga vários destinos da cidade oriundos de iniciativas que decorrem das parcerias estratégicas entre a academia, o poder público, o terceiro setor e a iniciativa privada. A universidade é um dos destinos estratégicos da rota.

Ao colocar a universidade como ponto central, é possível entender suas relações internas e externas na área da inovação e analisar como funciona seu ecossistema e avaliá-1o. A figura 5 apresenta o ecossistema da universidade estudada, que está situada na região Sul do Brasil. A representação do ecossistema foi construída baseada nas categorias utilizadas pela Universidade de Berkeley, cujo caso foi apresentado por Heaton, Siegel e Teece (2019). 
Figura 5 - Ecossistema de uma universidade estudada

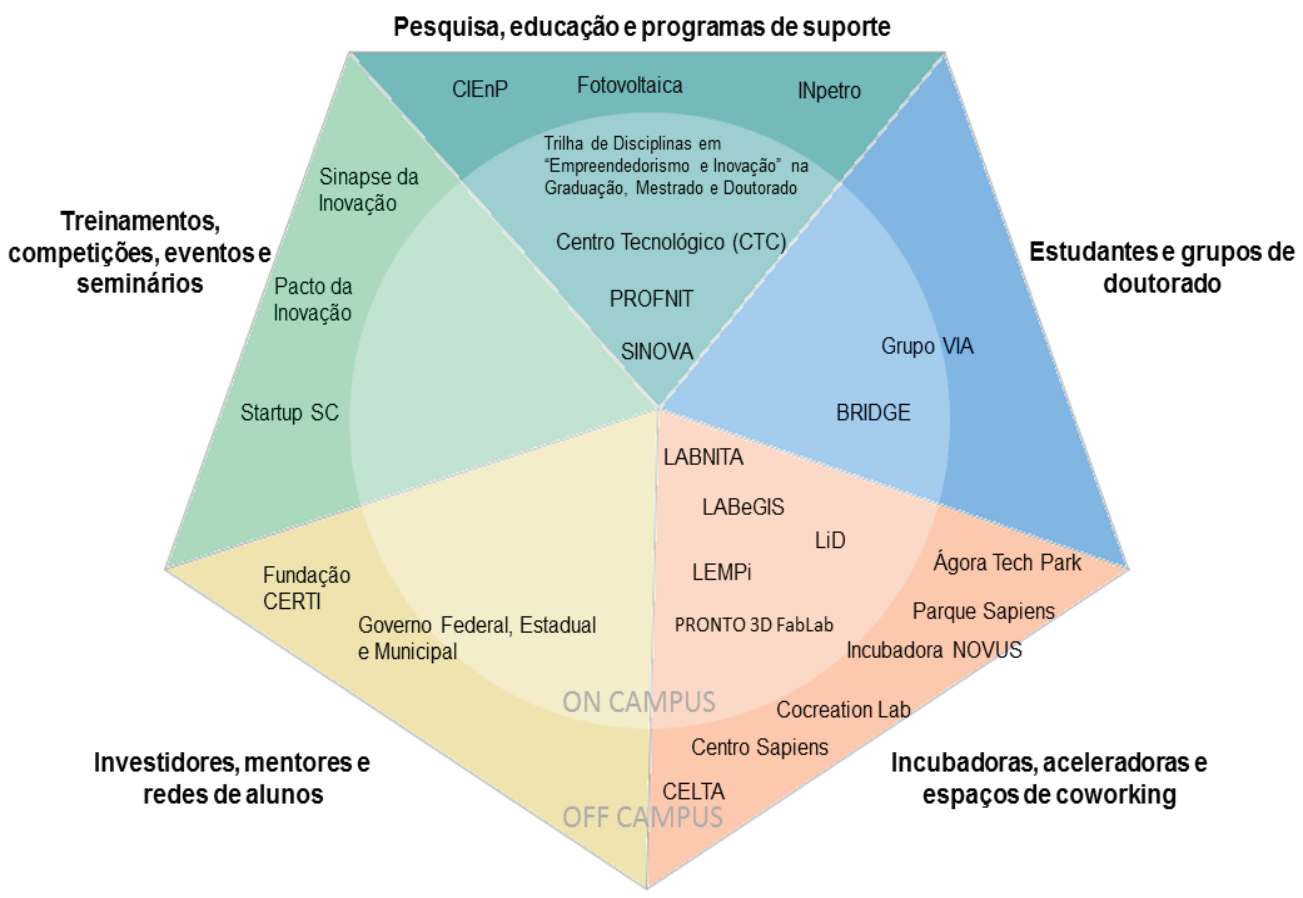

Fonte: elaboração própria (2019).

Observou-se que o ecossistema possui atores nos cinco eixos propostos pelo modelo de capacidades dinâmicas. A seguir, são apresentadas as evidências coletadas acerca de cada um desses itens.

\subsection{EIXO PESQUISA, EDUCAÇÃO E PROGRAMAS DE SUPORTE}

No eixo "pesquisa, educação e programas de suporte", verifica-se uma concentração de atores no ambiente universitário e alguns projetos que se expandem para fora do campus da instituição. Nessa instância, pode-se citar a existência de uma trilha que engloba as disciplinas disponibilizadas pela universidade nas temáticas de inovação, empreendedorismo e conhecimento, tanto para graduação quanto para a pós-graduação. Esse mapeamento foi realizado por um grupo de estudo e facilita o direcionamento e otimiza a formação de alunos na temática.

A universidade também participa do Programa de Mestrado Profissional em Propriedade
Intelectual e Transferência de Tecnologia para Inovação - PROFNIT. Trata-se de uma contribuição social do Fórum Nacional de Gestores de Inovação e Transferência de Tecnologia FORTEC, em associação a Instituições de Ensino Superior, à formação de recursos humanos em nível de mestrado para atuar nas áreas de Propriedade Intelectual e Transferência de Tecnologia para Inovação, como Núcleos de Inovação Tecnológicas, Centros de Inovação Tecnológica, Agências de Fomento à Pesquisa, Desenvolvimento \& Inovação, entre outros ambientes de inovação. O público alvo do PROFNIT na universidade estudada é o de discentes que já tiveram contato com o tema em áreas como engenharia, administração, direito, contabilidade, relações internacionais, entre outros.

Em sua estrutura administrativa, a universidade conta com a Secretaria da Inovação - SINOVA, cuja missão é promover a inovação e o empreendedorismo por meio de parcerias e interações com diferentes atores, criando condições para que o saber filosófico, científico, artístico e tecnológico, produzido na Universida- 
de, possa ser revertido em prol da sociedade. A SINOVA presta atendimento sobre propriedade intelectual, criação de startups, orientações jurídicas e outros projetos. Ainda, conta-se com a unidade de ensino Centro Tecnológico - CTC com a finalidade de promover o desenvolvimento científico, tecnológico e cultural para a melhoria da qualidade de vida. Fora do campus, a universidade possui iniciativas no maior parque tecnológico da região. Por meio dessas parcerias, possui centros de pesquisa e desenvolvimento nas áreas de petróleo, gás e energia; fármacos e energia solar.

\subsection{EIXO ESTUDANTES E GRUPOS DE DOUTORADO}

Tratando-se do eixo "estudantes e grupos de doutorado", destaca-se o Grupo VIA e BRIDGE. O Grupo VIA é um grupo de pesquisa, vinculado ao Programa de Pós-Graduação em Engenharia e Gestão do Conhecimento. Tornou-se referência nacional em pesquisa sobre habitats de inovação, já tendo mapeado mais de sete mil habitats (TEIXEIRA; FELDEN; MACHADO JÚNIOR, 2018). É formado por professores e alunos que procuram transformar o conhecimento de forma tangível e utilitária para a sociedade, promovendo a transferência de conhecimento. Já o BRIDGE é um laboratório integrado ao Centro Tecnológico (CTC) e atua na pesquisa e desenvolvimento de soluções tecnológicas digitais para contribuir com a qualificação da gestão pública. É formado por alunos de graduação, pós-graduação e profissionais das áreas de qualidade de software, análise de sistemas, desenvolvimento web e mobile, design, gestão, suporte e administração.

\subsection{EIXO INCUBADORAS, ACELERADORAS E ESPAÇOS DE COWORKING}

No eixo "incubadoras, aceleradoras e espaços de coworking", é possível citar diversas iniciativas, tanto internas como externas, sendo um eixo bem desenvolvido no ecossistema. No campus da universidade, há laboratórios que facilitam o encontro de estudantes e disponibilizam as ferramentas adequadas para pesquisa e desenvolvimento em áreas inovadoras. No entanto, aproveitando o potencial da região, a universidade também atua em parceria com outros órgãos e empresas, valendo-se de estruturas como parques tecnológicos, incubadoras e espaços de coworking fora do seu campus.

Nesse sentido, destaca-se o Parque Sapiens, um parque de inovação que possui infraestrutura e dedica seu espaço para abrigar empreendimentos, projetos e outras iniciativas inovadoras estratégicas para o desenvolvimento de uma região. $\mathrm{O}$ grande diferencial deste modelo é possuir uma solução inovadora para atrair, desenvolver, implementar e integrar as iniciativas com o objetivo de estabelecer um posicionamento diferenciado, sustentável e competitivo. Diversos prédios da universidade residem no parque, fazendo que existam diversos centros de pesquisa.

Como exemplo, a incubadora vinculada à universidade, NOVUS, fica localizada no parque. A NOVUS apoia o desenvolvimento de novos negócios criados por meio de projetos e ideias de alunos, professores e demais colaboradores.

Atuando em parceria, a universidade, o Parque Sapiens e a Prefeitura da cidade criaram o Centro Sapiens, uma incubadora criativa que visa transformar uma região em um distrito criativo, por meio de um processo denominado revitalização urbana e por meio do fomento da economia criativa local. Nesse local, atua o CocreationLab, pré-incubadora e espaço de coworking. Esse espaço visa desenvolver o empreendedorismo e transformar ideias em negócios. O CocreationLab é operado pela universidade por meio de grupos de alunos e professores.

A universidade é cofundadora do Instituto Ágora de Ciência e Tecnologia, uma entidade sem fins lucrativos, em parceria com empresas da região. O Ágora conta com aceleradoras, espaços de coworking, incubadoras, startups, centros de pesquisa, agências, investidores, 
empresas de base tecnológica e de serviços. $\mathrm{O}$ parque nasceu para fomentar o ecossistema e promover conexões, além de planejar e construir, de forma colaborativa, um centro de referência em inovação que possa funcionar como laboratório de cidades humanas e inteligentes.

Ainda se destaca a incubadora CELTA Centro Empresarial para Laboração de Tecnologias, que nasceu na década de 1980 com o objetivo de viabilizar um promissor setor econômico, einstalou-se nas proximidades da universidade, aproveitando os talentos e o conhecimento gerados pela instituição. A CELTA pertence à fundação CERTI - Centros de Referência em Tecnologias Inovadoras. Por sua vez, a Fundação CERTI oferece soluções para diferentes demandas de empresas privadas, instituições governamentais e terceiro setor em todo o Brasil. Utiliza sua própria estrutura interna de Centros de Referência em Tecnologias Inovadoras (CRITs) sendo a ponte entre o conhecimento gerado na universidade e as necessidades do mercado, utilizando os resultados de pesquisas básicas e aplicando no desenvolvimento de produtos. Além da própria universidade, participaram da constituição da CERTI, como Entidades Membro, empresas privadas e públicas e órgãos dos governos federal e estadual.

\subsection{EIXO INVESTIDORES, MENTORES E REDES DE ALUNOS}

Em relação ao eixo "investidores, mentores e redes de alunos", por tratar-se de uma universidade pública, o fomento advém muito mais de programas de governo. Há uma legislação específica no estado que estabelece medidas de incentivo à pesquisa científica e tecnológica e à inovação no ambiente produtivo, visando à capacitação em ciência, tecnologia $\mathrm{e}$ inovação, o equilíbrio regional e o desenvolvimento econômico social sustentável do Estado. No âmbito municipal, também há a lei municipal da inovação, que dispõe sobre sistemas, mecanismos e incentivos à atividade tecnológica e inovadora, visando ao desenvolvimento sustentável do município. Essa lei caracteriza o município como capital da inovação, com o objetivo de identificar a participação das entidades integrantes do Sistema Municipal de Inovação e de Arranjos Promotores de Inovação credenciados, nas ações de inovação do Município e indicar a procedência de serviços e produtos das empresas inovadoras.

Na universidade, também há normas específicas sobre os programas para, por exemplo, processos de incubação e startups, políticas de fomento e incentivo ao empreendedorismo, relação da universidade com fundações de apoio, propriedade e a gestão de direitos relativos à propriedade intelectual. Nota-se a atenção da universidade à necessidade de promover as políticas de desenvolvimento e fortalecimento da inovação científica e tecnológica mediante o estímulo à construção de ambientes especializados e cooperativos de inovação. Nas normas, é evidenciado que a incubação de empresas dentro da universidade deve ser direcionada, em primeiro lugar, para apoiar estudantes, bem como servidores docentes e técnico-administrativos e a comunidade em geral, de forma a terem uma alternativa profissional diferencia$\mathrm{da}$, e, em segundo lugar, como um ponto de transferência de know-how, ciência e tecnologia para o setor privado. Outro ponto destacado é que o fomento ao empreendedorismo do estudante é o caminho pelo qual a universidade pode modificar a realidade à sua volta de uma forma construtiva, beneficiando a sociedade.

\subsection{EIXO TREINAMENTOS, COMPETIÇÕES, EVENTOS E SEMINÁRIOS}

Em relação ao eixo "treinamentos, competições, eventos e seminários", percebeu-se que a universidade apoia e sedia grandes eventos da temática inovação. Cita-se o Sinapse da Inovação, programa que busca transformar e aplicar as boas ideias geradas por estudantes, pesquisadores e profissionais de diferentes setores do conhecimento e econômicos em negócios de sucesso. A universidade estudada é 
instituição parceira do evento e destaca-se no número de alunos com ideias aprovadas no programa. Além desse evento, também se destaca na região o projeto Startup $\mathrm{SC}$, cujo principal objetivo é fortalecer os startups digitais por meio da difusão da cultura empreendedora e da profissionalização da gestão de seus empreendimentos com ações de capacitação, inovação e mercado. No projeto, são realizadas diversas ações para todo tipo de empreendedor, desde a pessoa que tem uma ideia e quer iniciar um startup, até o empreendedor que já possui um startup e precisa acelerar seu crescimento.

A universidade ainda participa, com um grupo de mais de 20 entidades, do Pacto pela Inovação. A proposta do Pacto é a execução de um conjunto de ações estratégicas definidas de forma alinhada entre as entidades do ecossistema, cada uma delas focando em seu próprio público-alvo, mas contribuindo para o fortalecimento e a solução das principais defasagens do ecossistema de empreendedorismo e inovação.

O estudo deste ecossistema permitiu observar que a universidade estudada possui, entre as suas características, as capacidades dinâmicas, haja vista as diversas iniciativas de integração entre competências externas e internas visando à adaptação às mudanças e à promoção da inovação (TEECE; PISANO; SHUEN, 1997). Além disso, avaliando o ecossistema estudado e a interação com os atores de cada eixo, conclui-se que a universidade se encontra no estágio de desenvolvimento, segundo a hipótese de Heaton, Siegel e Teece (2019).

Entre os pontos fortes do ecossistema, cita-se o envolvimento de líderes locais e governo para desenvolver, cada vez mais, a região na área de empreendedorismo e inovação. Além disso, destaca-se a integração entre os atores do ecossistema, facilitando o fluxo de informações e o trabalho colaborativo de cada ator, contribuindo com a sua área de atuação, que é característica de ecossistemas bem-sucedidos. A universidade atua junto de outras entidades, com parcerias para projetos e eventos, elaboração de legislação, políticas de fomentos, ocupação de espaços e aproveitamento de estruturas. Ainda, conta em sua estrutura com setores de apoio para transferência de tecnologia para potenciais clientes de tecnologia patenteada. Assim, os pontos elencados por Heaton, Siegel e Teece (2019) para universidades em estágio de desenvolvimento foram todos encontrados no estudo da universidade da região sul do país.

Para que a universidade avance em seu desenvolvimento, é necessário permanecer fortalecendo suas parcerias com os demais atores do ecossistema. Ademais, visto que sua estrutura é compartilhada, contando com a colaboração de agentes externos, seu planejamento precisa estabelecer suas metas de relacionamento e uso de recursos.

\section{CONCLUSÕES}

Esta pesquisa buscou avaliar o ecossistema de inovação de uma universidade no Sul do Brasil por meio da estrutura de capacidades dinâmicas proposta por Heaton, Siegel e Teece (2019). Mais especificamente, comparou-se o ecossistema estudado com o caso da Universidade de Berkeley apresentado pelos mesmos autores. Em ambos os ecossistemas, os elementos elencados para universidades em estágio de desenvolvimento foram encontrados. O papel estratégico da universidade no desenvolvimento do ecossistema foi evidenciado ao longo da análise, bem como as particularidades do ecossistema da região.

O ecossistema foi avaliado mediante os seguintes os eixos: pesquisa, educação e programas de suporte; estudantes e grupos de doutorado; incubadoras, aceleradoras e espaços de coworking; investidores, mentores e redes de alunos e treinamentos, competições, eventos e seminários. A análise do ecossistema indica que ele está no estágio de desenvolvimento, ou seja, a universidade atua como uma consolidadora das ações e as redes e opções de financiamento estão estabelecidas.

Entre as características positivas do ecossistema, pode ser citada a quantidade de iniciativas inovadoras dentro e fora da universidade. Outro aspecto particular do caso estudado é a rede 
de parceiros construída para o desenvolvimento do ecossistema. Para estudos futuros, sugere-se incorporar ao estudo de caso outras fontes de evidências, como entrevistas e observações diretas. Além disso, outros ecossistemas brasileiros podem ser mapeados por meio do mesmo modelo, para fins de comparação e aprendizado. Assim, entende-se que o ecossistema estudado ainda está em desenvolvimento, eventualmente sendo necessárias políticas que integrem a gama de iniciativas que estão sendo realizadas.

\section{REFERÊNCIAS}

ACATE. Tech Report ACATE 2019: Panorama Do Setor De Tecnologia Catarinense. 2019. Disponível em: www.acate.com.br. Acesso em: 24 dez. 2019.

AUDY, Jorge. A inovação, o desenvolvimento e o papel da Universidade. Estudos avançados, v. 31, n. 90, p. 75-87, 2017.

BAGNATO, V. S. Inovação: da teoria à prática. In: PERUSSI FILHO, Sergio; BAGNATO, Vanderlei S.; BARRIONUEVO, Wilma. Caminhos da inovação: a visão de cientistas, educadores, empreendedores e agentes de inovação. [S.l.: s.n.], 2012. p. 19-33.

BENITEZ, Guilherme Brittes; AYALA, Néstor Fabián; FRANK, Alejandro Germán. Industry 4.0 innovation ecosystems: an evolutionary perspective on value cocreation. International Journal of Production Economics, p. 107735, 2020 .

BRASIL. Ministério da Ciência, Tecnologia, Inovações e Comunicações. 2018. Disponível em: https://www.mctic.gov.br/mctic/opencms/ inovacao/index.html. Acesso em: 30 nov. 2019.

CHESBROUGH, Henry. Open innovation: a new paradigm for understanding industrial innovation. Open innovation: Researching a new paradigm, v. 400, p. 1-19, 2006.
CHESBROUGH, Henry W. The new imperative for creating and profiting from technology. Open Innovation, 2003.

DODGSON, Mark; GANN, David. Inovação. [S.l.]: L\&PM, 2014.

DRESCH, Aline; LACERDA, Daniel Pacheco; ANTUNES JÚNIOR, José Antonio Valle. Design science research: método de pesquisa para avanço da ciência e tecnologia. [S.l.]: Bookman, 2015.

DUTTA, Soumitra; LANVIN, Bruno; WUNSCH-VINCENT, Sacha. Global innovation index 2018: energizing the world with innovation. [S.l.] : WIPO, 2018.

EISENHARDT, Kathleen M.; GRAEBNER, Melissa E. Theory building from cases: opportunities and challenges. Academy of management journal, v. 50, n. 1, p. 25-32, 2007.

ETZKOWITZ, Henry. Innovation in innovation: The triple helix of university-industry-government relations. Social science information, v. 42, n. 3, p. 293-337, 2003.

ETZKOWITZ, Henry; ZHOU, Chunyan. Hélice Tríplice: inovação e empreendedorismo universidade-indústria-governo. Estudos avançados, v. 31, n. 90, p. 23-48, 2017.

HEATON, Sohvi; SIEGEL, Donald S.; TEECE, David J. Universities and innovation ecosystems: a dynamic capabilities perspective. Industrial and Corporate Change, v. 28, n. 4, p. 921-939, 2019.

JACKSON, Deborah J. What is an innovation ecosystem. National Science Foundation, v. 1, n. 2, 2011.

MOORE, James F. Predators and prey: a new ecology of competition. Harvard business review, v. 71, n. 3, p. 75-86, 1993. 
OCDE. Manual de Oslo: diretrizes para coleta e interpretação de dados sobre inovação. Brasília: OCDE, Finep, 2005.

PABLO, Amy L. et al. Identifying, enabling and managing dynamic capabilities in the public sector. Journal of management studies, $\mathrm{v}$. 44, n. 5, p. 687-708, 2007.

SEBRAE. O empreendedorismo nas universidades brasileiras. 2017. Disponível em: https://www.sebrae.com.br/sites/PortalSebrae/ artigos/o-empreendedorismo-nas-universidades-brasileiras, 6ad3352450608510 VgnVCM1000004c00210aRCRD. Acesso em: 1 dez. 2019.

SILVA, Fabiane Padilha da et al. Gestão da inovação. Porto Alegre: SAGAH, 2018.

TEECE, David J. Managing the university: Why "organized anarchy" is unacceptable in the age of massive open online courses. Strategic Organization, v. 16, n. 1, p. 92-102, 2018.

TEECE, David J.; PISANO, Gary; SHUEN, Amy. Dynamic capabilities and strategic management. Strategic management journal, v. 18, n. 7, p. 509-533, 1997.

TEIXEIRA, Clarissa Stefani; FELDEN, Érico Pereira Gomes; MACHADO JÚNIOR, José Eduardo. Habitats de Inovação de Florianópolis: Os ambientes que transformam o ecossistema de inovação e empreendedorismo. Florianópolis: Perse ed., 2018.

TIDD, Joe; BESSANT, Joe. Gestão da inovação-5. [S.l.]: Bookman, 2015.

TOLSTYKH, Tatyana; GAMIDULLAEVA, Leyla; SHMELEVA, Nadezhda. Approach to the Formation of an Innovation Portfolio in Industrial Ecosystems Based on the Life Cycle Concept. Journal of Open Innovation: Technology, Market, and Complexity, v. 6, n. 4, p. 151, 2020.
TORLIG, Eloisa Gonçalves da Silva; RESENDE JÚNIOR, P. C. Uma discussão sobre o papel das universidades nos ecossistemas de inovação. TMS Algarve 2018: Tourism \& Management Studies International Conference, 2018.

TROTT, Paul J. Gestão da inovação e desenvolvimento de novos produtos. [S.l.] : Bookman, 2012.

YIN, Robert K. Estudo de Caso: planejamento e métodos. [S.l.]: Bookman, 2015.

YOUTIE, Jan; SHAPIRA, Philip. Building an innovation hub: a case study of the transformation of university roles in regional technological and economic development. Research policy, v. 37, n. 8, p. 1188-1204, 2008. 